\title{
Bone marrow suppression induced by high dose valproic acid
}

Takamasa Kishi, Naoto Fujita, Hiroshi Kawaguchi, Minenori Ishimae, Koji Watanabe, Takeo Tanaka

\begin{abstract}
A girl with intractable epilepsy who received high dose valproic acid showed bone marrow suppression, which improved after the end of valproic acid treatment and the administration of supportive treatments. Valproic acid markedly suppressed the in vitro colony growth in this patient. It is believed that high dose valproic acid treatment directly suppressed the growth of haematopoietic progenitors, resulting in bone marrow failure.
\end{abstract}

(Arch Dis Child 1994; 71: 153-155)

The reported adverse haematological effects of valproic acid treatment include thrombocytopenia and platelet dysfunction. Less common haematological toxicities included leucopenia and bone marrow failure. ${ }^{12}$ The pathophysiology of bone marrow failure remain unknown. It has been postulated that valproic acid has a possible direct toxic effect on bone marrow progenitor cells. ${ }^{3}$ We report here the case of a girl who had severe erythrocyte hypoplasia and thrombocytopenia during treatment with valproic acid. The aim of our study was to elucidate the pathophysiology of bone marrow suppression in this patient by determining the toxicity of valproic acid on the in vitro colony growth of haematopoietic progenitors.

\section{Case report}

A 9 month old girl with retarded growth and development and intractable epilepsy was admitted to the National Kure Hospital because of partial seizures and petechiae. Her neonatal history was uneventful and her weight at birth was $2900 \mathrm{~g}$. She was well until she was 1 month old, when she had brief generalised seizures associated with nausea. She later had partial seizures with facial automatism. These seizures did not respond to conventional doses of several antiepileptic drugs, including valproic acid. As she continued to have partial seizures, the dose of valproic acid was progressively increased to $64 \mathrm{mg} / \mathrm{kg} /$ day. She had thrombocytopenia without haemorrhagic manifestations one month after starting the high dose valproic acid treatment.

On admission (13 April 1993) she was lethargic due to frequent partial seizures and her muscle tonus was slightly flaccid. There were several petechiae on her anterior chest. Initial laboratory studies gave the following values: haemoglobin concentration $94 \mathrm{~g} / \mathrm{l}$, packed cell volume $0 \cdot 30$, red blood cell count $3.05 \times 10^{12} / 1$, white cell count $3.9 \times 10^{9} / 1$, platelet count $6.0 \times 10^{9} /$ (figure). The serum concentration of valproic acid was $213 \mathrm{mg} / \mathrm{l}$ and the dose of the drug was reduced to 43 $\mathrm{mg} / \mathrm{kg} /$ day, resulting in a serum concentration of $101.9 \mathrm{mg} / \mathrm{l}$. On follow up the platelet count
Department of Paediatrics, National Kure Hospital, Kure, Japan

T Kishi

H Kawaguchi

$M$ Ishimae

$\mathrm{K}$ Watanabe

$\mathrm{T}$ Tanaka

Department of

Paediatrics,

Hiroshima University

School of Medicine,

Hiroshima, Japan

N Fujita

Correspondence to:

Dr T Kishi, Department of Paediatrics, National Kure Hospital, Aoyamacho 3-1, Kure 737, Japan.

Accepted 15 February 1994

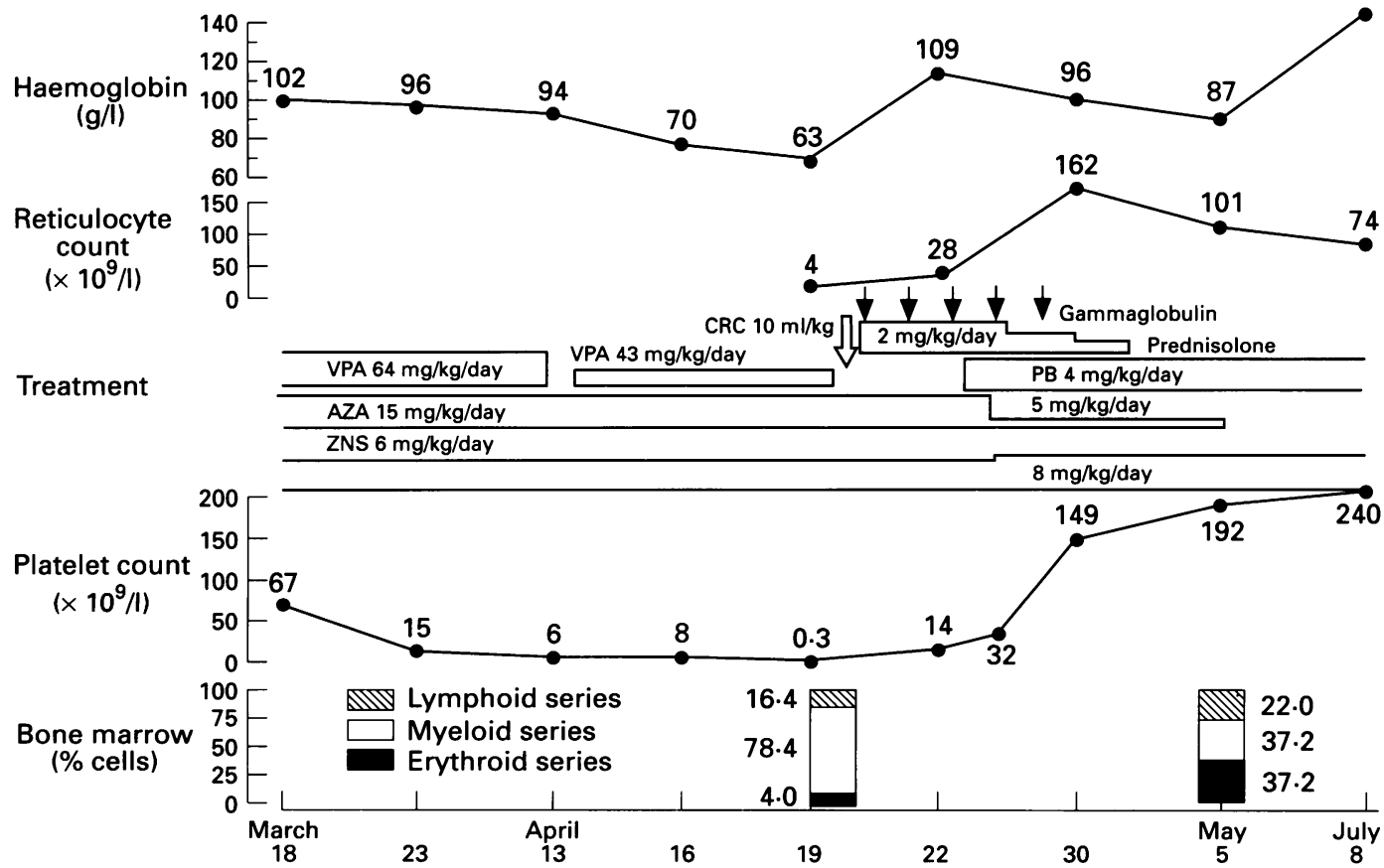

Clinical course. $V P A=$ valproic acid; $P B=$ phenobarbitone; $A Z A=$ acetazolamide; $Z N S=$ zonisamide; $C R C=$ concentrated red blood cell suspension. 
In vitro effects of valproic acid on haematopoietic colony growth

\begin{tabular}{|c|c|c|c|c|}
\hline \multirow{3}{*}{$\begin{array}{l}\text { Dose of } \\
\text { valproic acid } \\
(m g / l)\end{array}$} & \multicolumn{4}{|l|}{ No of colonies } \\
\hline & \multicolumn{2}{|l|}{$C F U-G M^{*}$} & \multicolumn{2}{|l|}{$C F U-E^{\star}$} \\
\hline & Normal control & Patient & Normal control & Patient \\
\hline $\begin{array}{r}0 \\
50 \\
100 \\
200\end{array}$ & $\begin{array}{c}204(100) \\
262(128) \\
296(145) \\
64(31)\end{array}$ & $\begin{array}{r}40(100) \\
80(200) \\
112(280) \\
20(50)\end{array}$ & $\begin{array}{l}10(100) \\
14(140) \\
\text { NAt }^{\dagger} \\
0\end{array}$ & $\begin{array}{l}4(100) \\
4(100) \\
1(25) \\
0\end{array}$ \\
\hline
\end{tabular}

The data in parentheses are the percentage change induced by valproic acid in the number of colonies in valproic acid-free culture.

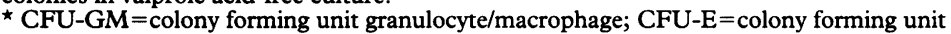
erythroid.

†Not available. unit granulocyte/macrophage (CFU-GM) assays. Culture studies were performed in triplicate with and without the addition of valproic acid (Kyowa-Hakko Co Ltd, Japan). Cultures were incubated for 10 days at $37^{\circ} \mathrm{C}$ in a humidified atmosphere with $5 \%$ carbon dioxide. The sheets of agar placed on the slide glass were double stained by esterases. Colonies of more than 40 cells were counted under the microscope and the number of CFU$\mathrm{GM} / 10^{5}$ bone marrow cells was calculated.

COLONY FORMING UNIT ERYTHROID ASSAYS A methylcellulose technique, as described previously, ${ }^{5}$ was used for the colony forming unit erythroid (CFU-E) assay. Colonies of more than 40 cells were counted under an inverted microscope and the number of CFU-E $/ 10^{5}$ bone marrow cells was calculated. folic acid $(26.3 \mathrm{mg} / 1$; normal $3 \cdot 1-8.3 \mathrm{mg} / \mathrm{l})$ and vitamin B12 (more than $1600 \mathrm{ng} /$; normal 230-800 ng/l) were increased. Antinuclear antibodies and antiplatelet antibodies were negative. Examination of her bone marrow showed erythroid hypoplasia (myeloid/erythroid ratio 19.6) with decreased numbers of megakaryocytes and with the Pelger-Huet anomaly in the myeloid precursors.

Because of a worsening general condition and dyspnoea, a single transfusion of packed erythrocytes, $10 \mathrm{ml} / \mathrm{kg}$, was given on the seventh hospital day. In addition, the patient received a short course of intravenous prednisolone ( $2 \mathrm{mg} / \mathrm{kg} /$ day) and gammaglobulin (110 $\mathrm{mg} / \mathrm{kg} /$ day) administered intravenously for five days. Marked resolution of the bone marrow suppression as evidenced by reticulocytosis $\left(162 \times 10^{9} / 1\right)$ and an increase in haemoglobin values $(96 \mathrm{~g} / \mathrm{l})$ and platelet count $\left(149 \times 10^{9} / \mathrm{l}\right)$, occurred 10 days after the discontinuation of valproic acid and with these supportive treatments. Instead of valproic acid, phenobarbitone was prescribed and the dose of zonisamide was increased from 6 to $8 \mathrm{mg} / \mathrm{kg} /$ day. Acetazolamide, which seemed to be ineffective, was gradually tapered. Slight leucocytosis $\left(10 \cdot 1 \times 10^{9} / 1\right)$ seemed to be due to a rebound phenomenon in the recovery phase of the suppressed bone marrow. A second bone marrow aspiration showed an increase in the erythroid series (myeloid/erythroid ratio $1 \cdot 1$ ) and normal megakaryocyte and myeloid cell numbers without the Pelger-Huet anomaly.

\section{Methods}

BONE MARROW COLLECTION

Samples of the patient's bone marrow were collected during the acute and convalescent periods after informed consent was obtained from her parents according to institutional standards. A normal bone marrow sample was obtained as a control from an adult donor for bone marrow transplantation after informed consent.

\section{COLONY FORMING UNIT}

GRANULOCYTE/MACROPHAGE ASSAYS

A single layer soft agar technique, as described previously, ${ }^{4}$ was used for the colony forming

\section{Results}

To assess a possible direct toxic effect of valproic acid on bone marrow progenitor cells, we studied CFU-GM and CFU-E in the presence of three doses of valproic acid (50, 100, and $200 \mathrm{mg} / \mathrm{l}$ ) (table). In CFU-GM at valproic acid concentrations less than 100 $\mathrm{mg} / \mathrm{l}$, inhibition was not observed compared with the control culture without valproic acid. At a high concentration of valproic acid (200 $\mathrm{mg} / \mathrm{l}$ ), similar to the serum concentration of our patient on admission, there was marked inhibition of CFU-GM growth. The colony growth was $31 \%$ (64 colonies) and 50\% (20 colonies) of that seen in control cultures without valproic acid in a normal control and our patient respectively.

In CFU-E, at concentrations greater than $100 \mathrm{mg} / \mathrm{l}$, valproic acid markedly inhibited CFU-E growth in the normal control and the patient. There was only one colony $(25 \%$ of growth) in the cultures from the patient at a valproic acid concentration of $100 \mathrm{mg} / \mathrm{l}$. No colony growth was detected at a valproic acid concentration of $200 \mathrm{mg} / \mathrm{l}$ (table). These inhibitions were of the same order of magnitude in the two cell sources. Valproic acid was more toxic to CFU-E than to CFU-GM, however.

\section{Discussion}

In our patient, the peripheral blood and bone marrow findings indicated severe anaemia due to erythroid hypoplasia, amegakaryocytic thrombocytopenia, and the Pelger-Huet anomaly without neutropenia during valproic acid treatment. Valproic acid affected all three bone marrow cell lines. These cytopenias recovered after the discontinuation of valproic acid and concomitant supportive treatments and seemed to be due to valproic acid. These haematological abnormalities in bone marrow cells, which have been reported on only two previous occasions, ${ }^{12}$ seem to be rare complications of treatment with valproic acid. Smith and Boots postulated that the bone marrow suppression was most likely to be related to valproic acid and that valproic acid induced 
bone marrow suppression may explain the discrepancy between commonly reported decreases in platelet count and the relatively low incidence of platelet autoantibodies. ${ }^{1}$

Watts et al quantified CFU-GM and CFU-E in the presence of increasing doses of valproic acid to evaluate a possible direct toxic effect of valproic acid. ${ }^{3}$ They observed consistent dose dependent inhibition only in normal adult bone marrow. They did not determine whether patients with haematological abnormalities are more sensitive than normal controls to valproic acid toxicity. In our study bone marrow culture studies showed that valproic acid suppressed CFU-GM and CFU-E in vitro at the high concentration of $200 \mathrm{mg} / \mathrm{l}$, and that the degree of suppression was the same in the normal control and the patient. Therefore, the bone marrow suppression was probably the result of direct suppression by valproic acid, and our patient was not easily susceptible to bone marrow suppression by valproic acid. In the light of toxic effects of valproic acid on haematopoietic cells, neutropenia and anaemia might be common, but these cytopenias are indeed rare complications. The reason why these cytopenias do not develop remains unclear. Perhaps there are other factors involved.
Studies on the rational treatment of refractory epilepsy have reported the efficacy of treatment with high dose valproic acid. Thrombocytopenia and hypofibrinogenaemia were often seen with high dose valproic acid, but not abnormalities of the erythroid or myeloid series. ${ }^{6}$ In our studies, valproic acid did not inhibit bone marrow function at a concentration less than $100 \mathrm{mg} / \mathrm{l}$. There was marked in vitro suppression of bone marrow at the high valproic acid concentration of $200 \mathrm{mg} / \mathrm{l}$. We emphasise the need for close haematological monitoring of patients receiving high dose valproic acid treatment.

1 Smith FR, Boots $M$. Sodium valproate and bone marrow suppression. Ann Neurol 1980; 8: 197-9.

2 Ganick DJ, Sunder T, Finley JL. Severe hematologic toxicity of valproic acid. A report of four patients. Am $\mathcal{f}$ Pediar of valproic acid. A report of

3 Pike BL, Robinson WA. Human bone marrow colony growth in agar-gel. $\mathcal{F}$ Cell Physiol 1970; 76: 77-84.

4 Nakahata T, Ogawa M. Hemopoietic colony-forming cells in umbilical cord blood with extensive capability to generate mono- and multipotential hemopoietic progenitors. $\mathcal{f ~ C l i n}$ Invest 1982; 70: 1324-8.

5 Watt RG, Emamel PD, Zuckermann KS, Howard TH Valproic acid - induced cytopenias: evidence for a doserelated suppression of hematopoiesis. $\mathcal{F}$ Pediatr $1990 ; 117$ 495-9.

6 Ohtsuka Y, Amano R, Mizukawa M, Oka E, Ohtahara S Treatment of intractable childhood epilepsy with high-dose valproate. Epilepsia 1992; 33: 158-64. 